\title{
Heritage sporting events: theoretical development and configurations
}

\author{
Joël Pinson \\ Swiss Graduate School of Public Administration, IDHEAP, Université de Lausanne, \\ Joel.Pinson@unil.ch
}

The Version of Record of this manuscript has been published and is available in Journal of Sport \& Tourism, December 2016, http://www.tandfonline.com/toc/rjto20/current, http://dx.doi.org/10.1080/14775085.2016.1263578.

To cite this article: Pinson, J. (2017). Heritage sporting events: theoretical development and configurations. Journal of Sport \& Tourism, 21:2, 133-152, DOI:

$10.1080 / 14775085.2016 .1263578$

\begin{abstract}
Although sports heritage is increasingly recognized as a potential catalyst of tourism, heritage sporting events (HSEs) are still an emerging concept in the academic literature. Notions that associate sports events and heritage remain rare, and are usually analysed through the scope of nostalgia sport tourism. This can be partly explained by an inclination to associate the notion of heritage with conventional ideas about folklore and traditional culture. Through a constructivist approach of heritage, this contribution argues that contemporary sports events, which would generally have competition as their primary focus, might also be perceived as HSEs. A comprehensive framework, built on a multi-disciplinary literature review, is presented to show the process that transforms an initial resource (a sports event) into an accomplished resource (a HSE), which might represent a competitive advantage for the territory. A qualitative-comparative analysis is conducted among twenty-four sports events in the French-speaking part of Switzerland, to observe the configurations of HSEs and understand which characteristics are necessary for the perceptions of a sports event as a heritage good. Interestingly, this contribution shows that if the event needs to be sustainable in the territory to be perceived as a HSE, it is not sufficient. Indeed, a differentiation strategy should be set up to distinguish the event from other more or less similar events, to be perceived as an authentic feature of the territory by the local population.
\end{abstract}

Keywords: heritage sporting events; qualitative-comparative analysis; event-led strategies; perceived authenticity 


\section{Introduction}

In today's context of intense competition among destinations, cities, regions and countries have to find new strategies to promote their territory to tourists, companies, investors and residents (Hede, 2005; Mason \& Duquette, 2008; Misener \& Mason, 2008; Fourie \& Santana-Gallego, 2011; Vuignier, 2015). Event-led strategies - related to sport, culture or business - emerged as a tool to boost territorial development. When it comes to sports, these strategies are usually based on attracting exogenous resources (major international one-off events) to the territory. Although the benefits from hosting a sports event are difficult to measure and are often overestimated (Black \& Van der Westhuizen, 2004; Hede, 2005; Feddersen \& Maennig, 2012; Taks, 2016), many public officials believe that sport, and sports events especially, can be a catalyst for local development (Misener \& Mason, 2008). While some destinations were focusing on sports events to brand and promote their territory, other regions were developing strategies based on endogenous resources (local heritage). By focusing on the local identity and the unique features of the territory, these 'heritage-based' strategies can strengthen the economy and attract tourists, while having a positive impact on the quality of life and the territory attractiveness (Borghi, Mariotti \& Safarzadeh, 2011). However, synergies between these two types of strategies are rarely considered. Although many sports events have some heritage component (such as their main arena), local authorities usually underestimate their capacity to brand and promote the territory, while most of the academic research focused on major sports events.

For Ramshaw and Gammon (2015), it is possible to identify two types of heritage sporting events (HSEs), whether they have heritage or competition as their primary focus. On the one hand, we can identify sports events where the heritage dimension is a core feature. The Heritage Classic in ice hockey (Ramshaw, 2014), the Arctic Winter Games 
(Hinch \& de la Barre, 2007), the Dragon Boat Race in China or the Kirkpinar Oil Festival in Turkey (Pinson, 2016b) are some of the examples presented in the academic literature. Although most of these events have a competitive dimension - meaning one of their aims is to designate a winner - the celebration of the sports heritage or the local heritage is central to them. On the other hand, sports events, where the competitive/sporting dimension is a core feature, but that are still strongly linked to the local identity, can be identified. The Wimbledon Championships, the Paris-Roubaix cycling race, the Kentucky Derby or the Boston Marathon are some of the events that can be listed within this second category. Even if the events listed have an international exposure, many events at the national or local level can also be identified as such. This second type of HSEs are usually recurrent in the same location for many years (Chappelet, 2015) and are perceived by the visitors (both spectators and participants) as a good opportunity to experiment with the local heritage (Ramshaw \& Gammon, 2015). The idea that sports and sports events can offer a more authentic insight into a destination culture is not new (Crawford, 2004; Hinch \& Higham, 2011). In that perspective, HSEs might be an opportunity to engage with tourists interested to have a more intimate interaction with the local identity. However, HSEs is still an emerging concept in the academic literature. The process that leads from a sports event to a HSE needs to be better understood to develop further research and discuss managerial implications.

Therefore, this contribution analyses the construction process of HSEs. Before focusing on the methodology and the major results from this study, a multidisciplinary literature review is conducted to identify HSEs' characteristics. Based on them, a comprehensive framework - which shows the transformation of a sports event (seen as an initial resource) into a heritage sporting event (seen as an accomplished resource) - is created. A qualitative-comparative analysis (QCA) is conducted to observe the different 
configurations that lead to the perception of a sports event as a heritage good. Managerial and theoretical implications are discussed at the end of this contribution.

\section{Sport and Heritage}

Although the concept of heritage broadened in the last decades to refer also to intangible objects, such as the Kabuki theatre in Japan (inscribed in 2008 by UNESCO on the intangible cultural heritage list), sport and sports events are rarely recognized as such. For some authors (Pfister, 2011; Ramshaw, 2011; Gammon, Ramshaw \& Waterton, 2013; Hinch \& Ramshaw, 2014), sport has often been overlooked in heritage studies due to its representation of both popular culture and recent past, making it part of 'low' culture in comparison with 'high' culture, which is usually represented by heritage. However, this non-recognition of sport has evolved in the last decade both in the eyes of local authorities, who consider sports heritage as a potential tourist attraction, and the academics, who try to find other paths than mega-sports events for event-led strategies.

The growing number of sports museums, and their success as tourist attractions, can be seen as an indication that the heritage dimension of sport is getting recognized. The Olympic Museum in Lausanne is among the most visited museum in Switzerland (Pinson, 2016a), while Old Trafford (Manchester United stadium and its related museum) with over 250'000 visitors a year can be compared with some English Heritage's top visitor attractions (Wood, 2005). At the institutional level, the international council on monuments and sites (ICOMOS) celebrated the "Heritage of Sport" as their 2016 theme, while two wrestling disciplines - Ssirum from the Democratic People's Republic of Korea and Kazakh Kuresi from Kazakhstan - are under process for inscription on UNESCO's list in 2016. However, as mentioned by Ramshaw and Gammon (2005), when we speak about sports heritage, we need to distinguish the heritage of sport, which reflect the heritage that occurred (and continues to occur) on the field of play, from sport as 
heritage, where events and the accomplishments of athletes are becoming part of a grander narrative. In the academic literature, the connection between sport and heritage refers most of the time to a nostalgic imagery of sport. It can be observed through sports events featuring former famous athletes (such as the 'Trophée des Légendes' played during Roland Garros), sports events trying to recreate conditions of past practices, as the Winter Classic in ice hockey, which is a regular-season game played outdoors (Ramshaw, 2011) or newly built sports facilities, which deliberately embraced a nostalgic imagery of their sporting past (Mason, Duquette \& Scherer, 2005).

In a broader perspective, to see sport as heritage is based on the idea that heritage is not a finite resource (Howard, 2003) and that heritage goods are identified as such through a social construction (Boisseaux, Knoepfel, Laesslé \& Tippenhauer, 2012). This idea is reinforced by Ramshaw (2011, p.4) when he mentioned that the question should not be 'whether sport can be heritage, but rather how is sport heritage constructed'. The way HSEs are defined in this research is influenced by this constructivist approach towards heritage. Therefore, since the heritage dimension of sport is seen as a social construct, the actors' strategies to distinguish their event from other more or less similar events need to be considered.

\section{Sports events as heritage goods}

One of the first difficulties in a research on HSEs is to identify sports events that could be classified under this concept. When a specific label exists, like the world heritage by UNESCO or to another extent the protected designation of origin by the European Union, objects with a heritage dimension are already identified. However, sports events are usually not recognized as such. In 2003, the adoption by UNESCO of the Convention for the Safeguarding of the Intangible Cultural Heritage made an opening for the inscription of sports events on UNESCO's list. Indeed, in its article 2 (UNESCO, 2003), the 
convention recognizes 'festive events' as potential manifestation of intangible heritage, such as the Carnival of Barranquilla in Colombia inscribed in 2008 (UNESCO, 2008). Since the creation of the convention, some sporting disciplines have been inscribed, such as the equitation in the French tradition (UNESCO, 2011). However, only three events (that can be seen as sports events) were inscribed so far: the Kirkpinar Oil Wrestling Festival in Turkey, the Naadam in Mongolia and the Dragon Boat Festival in China. In an interesting way, the nomination forms of these events (UNESCO, 2009, 2010a \& 2010b) are highlighting the cultural aspects of the events and not their sporting or competitive dimensions. The Kirkpinar's form highlights the cazgirs' prayers and the participants' traditional costumes, while the Naadam and the Dragon Boat Festival's forms are concentrating on the memorial ceremonies that take place during the events. This non-recognition of the heritage dimension of sports events - at least out of their cultural aspects - can also be explained by the fact that to date HSEs have been underresearched.

In the academic literature, different concepts can be linked to the notion of HSE. 'Special Events', 'Hallmark Events' and 'Signature Events' (Ritchie, 1984; Hall, 1989; Jago \& Shaw, 1998; Arcodia \& Robb, 2000; Sofield, 2003; Getz, 2008) are all concepts that describe events that have the capacity, either by their significance, their tradition or their quality to be seen as an integral part of their destination. The notion of 'site of memory' developed by Nora (1984) refers both to real or imagined 'places' that are connected with specific emotions and meanings for a group. By calling upon emotions and passions, sports events create deep-seated patterns of identification (Pfister, 2011) and, therefore, can be recognized as sites of memories. This capacity of an event to create a link between a specific activity and a territory is very important in a HSE's perspective. However, in most of the cases, the concepts mentioned above do not consider the event 
as a heritage good or as having a heritage essence. Some more attention has been given to the heritage dimension of some cultural events. In these studies ${ }^{1}$, the question of the events' authenticity, or at least of its perception, is central. Although the concept of authenticity is a delicate one to deal with, Wang (1999) suggested that there are three types of authenticity: objective authenticity (which refer the authenticity of the original), constructive authenticity (which recognize the tourists own meaning of reality) and the existential authenticity (which is linked to the person's self-experience). In relation to Wang's three types of authenticity, Hinch and Higham (2005) believe that sport and sports events, through the uncertainty of outcomes, the role of athletic display, the kinaesthetic nature of sport and the usual strong engagement in sport, are a good material to facilitate authentic cultural experience.

A first explicit association between sports events and heritage can be seen through the concept of 'Sport Heritage Attractions' (Ramshaw, 2011; Hinch \& Ramshaw, 2014). This concept refers to the desire, in North America in the first place, to maintain and sometimes create a link to an idealized and reclaimed sport past. However, most of the concepts listed above are defining sports events that have a strong connection to the territory and/or to the past. The allusion to the heritage dimension of the event remains rare and refers usually to some tangible aspects of the event or to a nostalgic vision of sport. This can be partly explained by what Waterton, Smith and Campbell (2006) refer to as the authorised heritage discourse following the Venice Charter. From this perspective, heritage is usually conceived as an immutable and bounded entity, which is most likely to take the form of a monument or a site. Furthermore, the inclination to associate the notion of heritage with conventional ideas about folklore and traditional

\footnotetext{
${ }^{1}$ See for instance: Chhabra, Healy and Sills (2003); Rinaudo (2005); or McCartney and Osti
} (2007). 
culture, as shown by Leimgruber (2010), might also play a part. Of course, many events within folkloric or traditional sports can be identified as HSEs. Major tournaments in Sumo, such as the Hatsu Basho in Tokyo (the opening tournament in January), might be good examples. In Switzerland, two of the most popular sports events in terms of TV audience come from traditional Swiss sports: the national finals in Swiss wrestling and cow fighting (Herens cattle). However, this contribution argues that contemporary sports events, which would generally have competition as their primary focus, can also be perceived as HSEs. For instance, Fleuriel and Raspaud (2011), in a study about the cycling race Paris-Roubaix, identified the cobblestones' areas and Roubaix's velodrome as the two main heritage features of the race. Nevertheless, it is the event that gives these two tangible objects a special value. In their study, the heritage essence of the event has been clearly identified, but was not further developed.

Recently, other authors tried to define HSEs, understood as sports events with a heritage essence. For Chappelet (2015, p.63), a heritage sporting event:

must belong to a specific place and be held there regularly, usually every year, sometimes every two years, without interruption other than under exceptional circumstances. The owner of the event must be a local organisation, generally a notfor-profit association or a local council, but not an international organisation.

For this author, it is only through a long historical process that a sports event can become a heritage good. The four characteristics identified in Chappelet's study (the recurrence, the specific location, the local governance and the longevity) are influencing the sustainability of the event on the territory. By reinforcing the territorial integration of the event, these characteristics can favour over time its recognition as a heritage good. However, if the sustainability of the event on the territory is necessary to perceive a sports event as a HSE, it is not sufficient. Indeed, some sports events, especially at the local level, exist for a very long time and cover some or all these characteristics without being 
recognized as heritage by the local population. For instance, the Nations Cup, a roller hockey tournament created in Montreux in 1921, comes back every two years in the same location for the past ninety-five years and is owned by a non-for profit organisation, but is not perceived as a HSE by the population, as it will be presented later in this study. Therefore, it is necessary to look at how HSEs distinguish themselves from other sports events to be perceived as a heritage good.

\section{The construction of heritage sporting events}

In his study, Bessy (2014) argues that HSEs usually look for a strategic position that allows them to be differentiated from other sports events. For Boisseaux et al. (2012), the differentiation of a heritage good is taking place through the interaction among three elements: the know-how, the infrastructures and the reception dispositions. In a HSE's perspective, the 'know-how' refers to the capacity of the actors to produce and maintain the event. For the owner, it is important to show that this know-how is unique to their event and that without it the event would be jeopardized. The 'infrastructures' are all the tangible symbols linked to the identity of the event (that may be, the land, the main arena, the logo, the anthems and so on). As shown by Chalip (2000), these symbols can juxtaposed with others and engender a sense of the sacred. Finally, the 'reception dispositions' refer to the belief in the special value of the event by the actors (both spectators and athletes). This last dimension is usually constructed through the narratives and myths (true or not) surrounding the good. The whole idea behind the differentiation strategy is for the good to be perceived by the public and the participants as an authentic feature of its territory. In the perspective of a HSE, this differentiation allows the event to go beyond the image of a sports competition to become a territorial resource able to contribute to local development. 
In that perspective, heritage can be perceived as a territorial resource in different ways. It can be a direct resource, when the heritage good strengthen the local economy and attract tourists, while it can also be considered as an indirect resource when it has a positive impact on the quality of life and the territory attractiveness (Borghi, Mariotti \& Safarzadeh, 2011). For Gumuchian and Pecqueur (2007, p.5), territorial resource can be defined as 'a constructed characteristic of a specific territory in a perspective of development'. The authors divide territorial resource into two dimensions. On the one hand, they define initial resource, which are unique features of the territory (that might be cultural, natural or historical). On the other hand, they distinguish accomplished resources, which are resulting from the actors' actions. Accordingly, sports events can be identified as initial resources (which represent a potential for the territorial development of a destination), while HSEs can be related to accomplished resources that might be seen as a competitive advantage for their territory.

From the understanding of HSEs as a resource and the characteristics previously identified, it is possible to create the comprehensive framework presented in Figure 1 to visualize the transformation process of a sports event into a HSE.

Figure 1: A comprehensive framework of HSEs

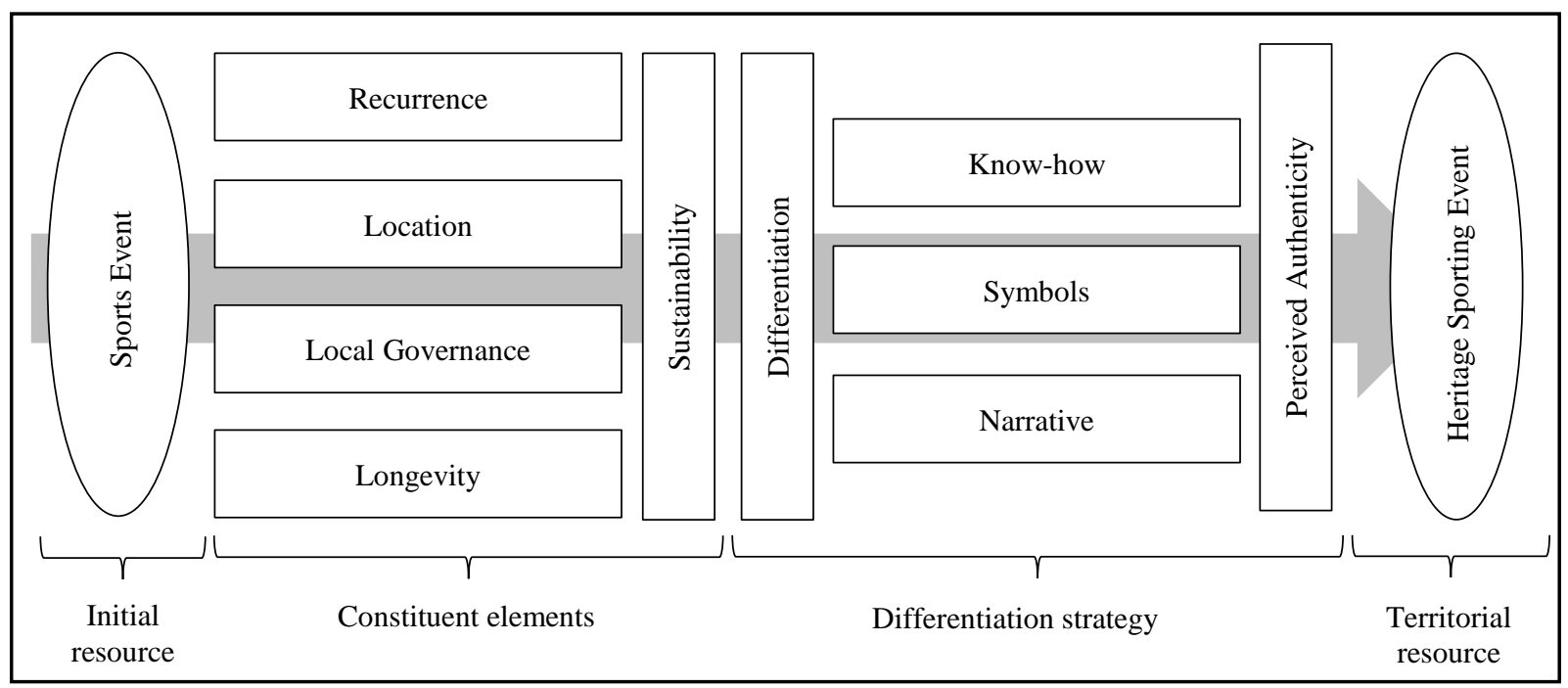


Adapted from Pinson's (2016b) study, Figure 1 presents the transformation of an initial resource (a sports event) into a territorial resource (a HSE). The constituent elements, by reinforcing each other, ensure the sustainability of the event in the territory, creating over time a strong identification between the host destination and the event. Sustainability does not only refer to the longevity of the event, but also to its capacity to adapt and evolve within the context over the years. For instance, the local governance of the event involves usually a strong implication of the local authorities in the organisation of the event (through subsidies, human resources, free public services such as security or the direct organisation of the event). Therefore, a change in the elected officials might impact the organisation of the event, if not jeopardize it. Consequently, the network surrounding the event needs to be strong enough to evolve and to integrate new stakeholders. The differentiation process will then highlight the event's unique features (at least as communicated by the organizers) and allow its perception as a HSE. In Figure 1, the infrastructures and reception dispositions, presented by Boisseaux and al. (2012), are replaced by the notions of symbols and narrative. The symbols cover all the tangible elements of the events that reinforce its uniqueness (such as the logo, the anthem, the land, the stadium and so on). The notion of infrastructures might have been too narrow or misunderstood. For the narrative, it can be explained by the angle this research is taking to observe the differentiation strategy. Indeed, the event's communication and the media coverage are used to observe how this differentiation is taking place. Therefore, more than the reception dispositions of the persons consuming the good, it is how the 'story is told' that is considered, and by consequence the narrative supporting the event. Of course, the aim of the narrative is to influence its perception by the population. This last comment can be linked to Wang's (1999) concept of existential authenticity, where the perceived experience by the actor is central to the measurement of authenticity. When it comes to 
HSEs, the perceived authenticity of the event is of course very important in its construction as a heritage good. If some events can relate to objective historical facts or tangible elements that have a unique value (in terms of history or sports heritage), many times the perceived authenticity of the event is built through myths, anecdotes, nicknames and particular traditions surrounding the event. For instance, the narrative of the Swiss running competition Morat-Fribourg, which is perceived as a HSE - as it will be presented later in this study - is built around the myth of Marathon and the legendary soldier who runs to announce the victory. If the battle which is mentioned by the organisers of the event really happened (the Battle of Morat between Charle I, Duke of Burgundy and the Swiss Confederate Army), the myth of the soldier is used to legitimise the event by giving a historical dimension. Nevertheless, by building upon this myth, the race attracts around 12'000 participants (without counting the relatives who come to support), while Morat is only 6'000 inhabitants and Fribourg 36'000.

The comprehensive framework presented in Figure 1 gives a theoretical visualization of the transformation of a sports event into a HSE. Of course, not all the events perceived as HSEs have the same shape. The adjustments between the elements identified in Figure 1, especially regarding the differentiation process, will influence the configurations of HSEs.

\section{A qualitative-comparative analysis of HSEs}

To observe the different configurations of HSEs, a qualitative comparative analysis (QCA) was conducted for this study. QCA helps to test a hypothesis and to identify the combination of conditions that lead to a specific outcome in a group of cases. It combines the advantages of qualitative (case-oriented) and quantitative (variable-oriented) techniques. QCA is a very appropriate method for middle-range sample size (as it is the case for this study with 24 events). It helps to systematize the analysis, while you might 
have too few cases to study them quantitatively. QCA is based on principals of configurational causality, determining whether a condition is necessary (always present but with other factors), sufficient (always present, sole factor) or irrelevant in a pattern leading to a specific outcome. Therefore, it is indispensable to create a sample of cases with different outcomes. Contradictions, meaning that certain configurations might both indicate the presence and the absence of a specific outcome, are one of the elements observed through QCA. Tosmana (Cronqvist, 2011) and fs/QCA 2.5 (Ragin \& Davey, 2014), two computer software, were used to compare systematically each case against every other with regards to the conditions and the specific outcome. To that purpose, this research used a crisp-set QCA (csQCA), where the seven conditions (highlighted in Figure 1) and the outcome (in the case of this contribution, the perception of a sports event as a HSE) were coded according to the following dichotomy: 1 for their presence and 0 for their absence. Once groupings of cases are identified, a close reading gives the opportunity to observe how conditions interact to produce a common outcome. Therefore, the aim of QCA is not to establish a causal relation between the independent variables and the dependent variable, but to observe the different configurations of conditions that might lead to a common outcome.

\section{Inventory and identification of HSEs}

As mentioned before, since no list or label exists, one of the difficulties in research on HSEs is their identification. Therefore, the first step of this research was to do an inventory of potential HSEs for six cantons in the French-speaking part of Switzerland (Fribourg, Geneva, Jura, Neuchâtel, Vaud and Valais). Events were identified based on the constituent elements presented in Figure 1. However, to observe whether or not these characteristics are decisive to identify HSEs, some variation from the theory was included. To be listed, an event had to come back to the same location (that might be an 
area, a square or a finish line) every year or every two years, at least for the last twentyfive years ${ }^{2}$ (the length generally accepted to identify one generation [Mesure \& Savidan, 2006]). Representatives of sports and tourism offices from both the cantonal and communal level in Switzerland were then asked to validate or complete the inventory. Based on these characteristics and on the inputs from the state and tourism agencies' representatives, a list of 134 events was compiled ${ }^{3}$. Two events were added in the list, the Red Bull Crashed Ice and the Laax Open, to introduce variations within the characteristics (own by a private organisation, no-recurrence or newly created).

In order to gather the perception of the local population on these events, an online questionnaire was administrated on a sample of the population (selected according to their place of residency or origin) in May-June 2015. The questionnaire was sent to 175 people. The response rate was of $73 \%$ (128 responses). Apart from the respondents' perception of the events, they were also asked about their sport activity (both the frequency and the disciplines) and whether or not they already participated (as a spectator or a participant) to the events listed. These questions were created to evaluate the influence of proximity on the respondents' perception. Indeed, for Arnaud (2012), the proximity plays a significant role on the way an object is perceived as part of the local identity. Table 1 shows the 24 events selected for the QCA, half of them being perceived as HSEs by the respondents.

\footnotetext{
${ }^{2}$ This number is based on UNESCO's considerations that it needs at least two generations for an object to be potentially identified as a heritage good. In this study, only one generation was considered to select the cases.

${ }^{3}$ All supplementary resources are available from the author. 
Table 1: Perceived HSEs in the French-speaking part of Switzerland

\begin{tabular}{|c|c|c|c|c|}
\hline & Event & Code & Creation & Discipline \\
\hline \multirow{12}{*}{$\begin{array}{l}\text { In } \\
0 \\
0 \\
0 \\
0 \\
0 \\
0 \\
0 \\
0 \\
0\end{array}$} & Course de l'Escalade & ESCA & 1978 & Running \\
\hline & $20 \mathrm{~km}$ de Lausanne & $20 \mathrm{KM}$ & 1982 & Running \\
\hline & Athletissima Lausanne & ATHLE & 1977 & Athletics \\
\hline & Patrouille des Glaciers & PDG & 1943 & Ski Mountaineering \\
\hline & Morat-Fribourg & MT_FR & 1933 & Running \\
\hline & Finales Nationales de la Race d'Hérens & FN_CR & 1922 & Cow fighting \\
\hline & Festival International de Ballons & FIB & 1979 & Ballooning \\
\hline & Sierre-Zinal & SI_ZI & 1974 & Trail \\
\hline & Bol d'Or Mirabaud & $\mathrm{BO}$ & 1939 & Sailing \\
\hline & Prix de Lausanne & PX_LS & 1973 & Classical Dancing \\
\hline & CHI de Genève & $\mathrm{CHIG}$ & 1926 & Equestrian Sports \\
\hline & Marché-Concours de Saignelégier & MC_SA & 1897 & Equestrian Sports \\
\hline \multirow{12}{*}{$\begin{array}{l}\text { ज्ञ } \\
0 \\
0 \\
0 \\
0 \\
0 \\
0 \\
0 \\
0 \\
0 \\
0 \\
0\end{array}$} & Trophées du Muveran & MUVE & 1948 & Ski Mountaineering \\
\hline & Challenge BAMBI & BAMB & 1970 & Running \\
\hline & Coupe des Nations & CP_NA & 1921 & Roller Hockey \\
\hline & Omega European Master & EU_MAS & 1923 & Golf \\
\hline & Journée Lausannoise du Vélo & JLV & 1983 & Cycling \\
\hline & Marathon de Lausanne & MAR_LS & 1993 & Running \\
\hline & Translémanique & TRANS & 1983 & Sailing \\
\hline & Coupe de Noël & C_NOEL & 1934 & Swimming \\
\hline & La Mara & MARA & 1971 & Cross-Country Skiing \\
\hline & Tir historique de Morat & TIR_M & 1930 & Shooting \\
\hline & Red Bull Crashed Ice & RED_B & 2001 & Ice cross Downhill \\
\hline & Laax Open & LAAX & 2016 & Snowboard Freestyle \\
\hline
\end{tabular}

Table 1 highlights the events' name, date of creation, discipline, their perception as a HSE and the code name used for the QCA. A first look at the events perceived as HSEs shows their diversity. The disciplines go from traditional Swiss sports, such as the 'Finales Nationales de Race d'Hérens' in cow fighting, to contemporary running competitions with the '20 km de Lausanne'. Similarly, some events can easily be identified as sports competitions, such as 'Atheltissima', which is an international track and field competition, while other are in the boundary between sports and cultural events, for instance, the 'Prix de Lausanne' a competition for young dancer in classical dancing. Although, the distinction between perceived HSEs and not perceived HSEs seems clear in Table 1, it needs to by qualify. Indeed, as mentioned before, the influence of the proximity (both in terms of space and sports practice) in the perception of the event by the population was also measured. Therefore, some of the events that are not perceived 
as HSEs in Table 1, when the whole sample is considered, are perceived as such when the proximity factor is measured. For instance, the Omega European Master of Golf in Crans-Montana is perceived as a HSE when only people from the Canton of Valais or golf players are considered. However, the proximity does not always influence the perception of the event by the population. The Trophées du Muveran, a skimountaineering competition created in 1948 and organized in the same location every year by a non-for profit organization, is not perceived as a HSE, even if only the responses of local residents or persons that practice this sport are analysed.

\section{Configurations of HSEs}

In the comprehensive framework presented in Figure 1, seven conditions are identified. Four of them are related to the sustainability of the event in the territory: the recurrence, the location, the local governance and the longevity. The other three conditions - the symbols, the know-how and the narrative - are linked to the differentiation of the event. However, Marx and Dusa (2011, p.114) show in their study that for a QCA of 24 cases, five conditions maximum (excluding the outcome) should be considered since the probabilities of generating results on random data are too high $(>10 \%)$. To reduce the number of conditions in this research, the experimental protocol presented in Table 2 was followed.

Table 2: QCA's protocol for HSEs (4 models)

\begin{tabular}{|c|c|c|c|c|c|c|c|c|c|}
\hline & \multicolumn{4}{|c|}{ Sustainability } & \multicolumn{3}{|c|}{ Differentiation } & \multirow{2}{*}{$\begin{array}{c}\text { Outcome } \\
\text { HSE }\end{array}$} & \multirow{2}{*}{$\begin{array}{c}\text { Observations } \\
\text { Too many conditions }\end{array}$} \\
\hline M1 & $\mathrm{A}$ & $\mathrm{B}$ & $\mathrm{C}$ & $\mathrm{D}$ & $\mathrm{E}$ & $\mathrm{F}$ & $\mathrm{G}$ & & \\
\hline M2 & A & B & $\mathrm{C}$ & $\mathrm{D}$ & & & & HSE & Contradictions \\
\hline M3 & & & & & $\mathrm{E}$ & $\mathrm{F}$ & $\mathrm{G}$ & HSE & Contradictions \\
\hline M4 & \multicolumn{4}{|c|}{$A^{*}$} & $\mathrm{E}$ & $\mathrm{F}$ & $\mathrm{G}$ & HSE & HSE's configurations \\
\hline
\end{tabular}

Table 2 is a simplification of the comprehensive framework presented in Figure 1. Under the sustainability of the event, $A$ is the recurrence, $B$ the location, $C$ the local governance and $D$ the longevity. Regarding the conditions of the differentiation process, $E$ is the 
know-how, $F$ the symbols and $G$ the narrative. $M I$ is the starting model with the seven conditions and was, therefore, not tested. $M 2$ and $M 3$ were used to study the sustainability and the differentiation process distinctively. For both analyses, contradictions were expected based on the theory. It means that these conditions might be necessary, but not sufficient to identify a sports event as a HSE. Therefore, similar configurations of conditions should be observed for sports events both perceived and not perceived as HSEs. Finally, M4 offers an analysis where the sustainability conditions were merged into one condition $\left(A^{\prime}\right)^{4}$ and the three conditions of the differentiation process are still present. Based on Table 2 and on the theory about both HSEs and QCA, it is possible to formulate the following hypothesis:

$$
\operatorname{SUST}(1) *(\mathrm{NAR}(1)+\mathrm{SYMB}(1)+\mathrm{KNO}-\mathrm{H}(1)) \Rightarrow \text { HSE }
$$

In QCA's language, the '*' stands for a logical 'and', while the sign '+' points to a logical 'or'. The ' 1 ' stands for the presence of the condition, while a ' 0 ' would mean its absence (for more information refer to Schneider and Wagemann, 2010, p. 414). The hypothesis formulated above means that to be perceived as a HSE by the population a sports event should be sustainable in the territory (SUST[1]) and differentiate itself from other more or less similar events, through either particular narratives (NAR[1]), specific symbols (SYMB[1]) or the display of a unique know-how (KNO_H[1]). The QCA was carried out following the protocol of Table 2 to confirm or refute this hypothesis.

As mentioned before, $M 1$ was not tested due to the high number of conditions. Contradictions were observed for both $M 2$ and $M 3^{5}$. Therefore, none of the seven

\footnotetext{
${ }^{4}$ To be coded as sustainable according to A', the event has to come back every year or every two years to the same location for at least 25 years and be owned by a local organisation.

${ }^{5}$ Truth tables for M2 and M3 are presented in the appendix.
} 
conditions highlighted by the comprehensive framework of Figure 1 are sufficient to perceive a sports event as a HSE. Table 3 shows the truth table based on the M4 model presented in Table 2 . There are 16 possible configurations combining the four binominal conditions. Five of the possible configurations (row 12 to 16) are not covered by empirical cases (which represent logical reminders). Four configurations (row 1 to 4), which combine 12 cases, have led to the perception of the event as a HSE. Finally, seven other configurations (rows 5 to 11 ), covering the other 12 cases, do not lead to the perception of a HSE.

Table 3: Truth Table of HSEs (M4)

\begin{tabular}{|c|c|c|c|c|c|c|c|c|}
\hline Row & Cases & $\begin{array}{l}\mathbf{N}^{\circ} \text { of } \\
\text { cases }\end{array}$ & NAR & SYMB & KNO_H & SUST & HSE & $\begin{array}{c}\text { Consistency } \\
\text { of HSE }=1\end{array}$ \\
\hline 1 & PDG & 1 & 1 & 1 & 1 & 1 & 1 & 1.00 \\
\hline 2 & $\begin{array}{l}\text { ESCA, 20KM, ATHLE, } \\
\text { MT_FR, SI_ZI, BO }\end{array}$ & 6 & 1 & 1 & 0 & 1 & 1 & 1.00 \\
\hline 3 & $\begin{array}{l}\text { FN_CR, PX_LS, CHIG, } \\
\text { MC_SA }\end{array}$ & 4 & 1 & 0 & 1 & 1 & 1 & 1.00 \\
\hline 4 & FIB & 1 & 0 & 0 & 1 & 1 & 1 & 1.00 \\
\hline 5 & MUVE, EU_MAS & 2 & 0 & 1 & 0 & 1 & 0 & 0.00 \\
\hline 6 & $\begin{array}{l}\text { BAMB, CP_NA, JLV, } \\
\text { C_NOEL, MARA }\end{array}$ & 5 & 0 & 0 & 0 & 1 & 0 & 0.00 \\
\hline 7 & MAR_LS & 1 & 0 & 1 & 0 & 0 & 0 & 0.00 \\
\hline 8 & TRANS & 1 & 0 & 0 & 0 & 0 & 0 & 0.00 \\
\hline 9 & TIR_M & 1 & 1 & 0 & 0 & 1 & 0 & 0.00 \\
\hline 10 & REDB & 1 & 1 & 0 & 1 & 0 & 0 & 0.00 \\
\hline 11 & LAAX & 1 & 1 & 1 & 0 & 0 & 0 & 0.00 \\
\hline 12 & - & 0 & 1 & 0 & 0 & 0 & - & - \\
\hline 13 & - & 0 & 1 & 1 & 1 & 0 & - & - \\
\hline 14 & - & 0 & 0 & 1 & 1 & 0 & - & - \\
\hline 15 & - & 0 & 0 & 1 & 1 & 1 & - & - \\
\hline 16 & - & 0 & 0 & 0 & 1 & 0 & - & - \\
\hline
\end{tabular}

As presented in Table 3, no sufficient conditions emerged from the analysis. However, a necessary condition can be observed for the presence of the outcome (the perception of a sports event as a HSE). A condition is defined as necessary if it must be present for a certain outcome to occur (Ragin, 2014). Table 4 and Table 5 show the results of the 
necessary conditions' tests for sports events perceived and not perceived as HSEs ${ }^{6}$. The consistency value of a necessary condition indicates the degree to which the condition overlaps with a particular outcome. A consistency value of 1.00 shows a necessary condition for a given outcome.

Table 4: Results of the necessary conditions' tests of HSEs

\begin{tabular}{lcc}
\hline \hline Conditions tested & Consistency & Coverage \\
\hline NAR & 0.92 & 0.79 \\
nar & 0.08 & 0.10 \\
SYMB & 0.58 & 0.64 \\
symb & 0.42 & 0.38 \\
KNO-H & 0.50 & 0.86 \\
kno-h & 0.50 & 0.35 \\
SUST & 1.00 & 0.60 \\
sust & 0.00 & 0.00 \\
\hline \hline
\end{tabular}

Table 5: Results of the necessary conditions' tests of non-HSEs

\begin{tabular}{lcc}
\hline \hline Conditions tested & Consistency & Coverage \\
\hline NAR & 0.25 & 0.21 \\
nar & 0.75 & 0.90 \\
SYMB & 0.33 & 0.36 \\
symb & 0.67 & 0.62 \\
KNO-H & 0.08 & 0.14 \\
kno-h & 0.92 & 0.65 \\
SUST & 0.67 & 0.40 \\
sust & 0.33 & 1.00 \\
\hline \hline
\end{tabular}

As shown by the consistency of 1.00 in Table 4, there is a single necessary condition for the perception of a HSE: the sustainability. The observation of the truth table - and as it is expected from the literature - shows that all cases that are perceived as HSEs are recurrent in the same location every year or every two years for at least 25 years and owned by a local entity (either a not-for-profit association, either a local council). The coverage of the sustainability as the only necessary condition of the perception of a HSE lies at 0.60 . It means that $60 \%$ of the cases that are sustainable in their territory are perceived as HSEs. There is in addition one other condition, which marginally fail the

\footnotetext{
${ }^{6}$ Uppercase letters represent the value 1 for a given binary condition, whereas lowercase letters represent the value 0 for that binary condition.
} 
test of necessity: the narrative. Only the 'Festival International de Ballons' (FIB) was not coded " 1 " for the narrative, which would have indicated a necessary condition. As mentioned before, the narrative plays an important part in the perception of a sports event as an authentic feature of the territory. Although, in some cases the linkage with the past or to a particular history of the event might be objective and have tangible representations, it is still necessary to highlight and maintain this uniqueness. For other cases, it is possible to build this uniqueness through a particular narrative, as it was mentioned before with Morat-Fribourg. Most of the events perceived as HSEs in this study do have a dedicated section on their website to highlight the event's history. These sections do not only give a chronology of the event, but would generally link the event to a historical event (such as a battle) or tell stories (myths and anecdotes) that will give the impression that the event is more than a sports competition to its participants (both spectators and athletes).

Unlike in the necessary conditions' tests for HSEs, there are no necessary conditions for the non-perception of a sports event as a HSE. Although none of the consistency values reach a level of 1.00 in Table 5, one condition only partially failed the test of necessity: the absence of a unique know-how. Unlike the narrative, and to another extend the symbols, the display of a specific know-how is less influenced by its perception by the participants. In the sample, the only event that is not perceived as a HSE and has a particular know-how is the Red Bull Crashed Ice. Since this event is not sustainable in the territory (not recurrent in the same location, privately owned and created recently), the display of its particular know-how is of course not linked to the territory. 
A csQCA test for sufficiency using the outcome of the perception of a sports event as a HSE, and including assumptions about logical reminders, leads to the following parsimonious solution?

$$
\operatorname{SUST}(1) *\left(\mathrm{NAR}(1) * \mathrm{SYMB}(1)+\mathrm{KNO} \_\mathrm{H}(1)\right)=>\mathrm{HSE}
$$

As indicated by this parsimonious solution, a sports event can be perceived as a HSE, if it is sustainable in the territory (SUST[1]) and a particular narrative (NAR[1]) as well as specific symbols (SYMB[1]) are present or if a unique know-how is displayed (KNO_H[1]). The coverage of this parsimonious solution is of $100 \%$, which means that all cases perceived as HSEs are explained by this solution. Of course, the result is the same for the consistency. This parsimonious solution point to two equifinal pathways. The first pathway - SUST(1)*NAR(1)*SYMB(1) - can be linked to Nora's (1984) notion of 'site of memory' and Chalip's (2000) research on the Olympic audiences. In that perspective, the narrative reinforces the special meaning of the event in a population and creates deep-seated patterns of identifications (Pfister, 2011). The symbols are tangible representations, which help people to connect with this special meaning (intangible dimension) by calling upon emotions and passions. The second pathway SUST(1)*KNO_H(1) - is in line with the initial hypothesis based on the theory. In that way, a sports event that is sustainable in the territory and that can show its uniqueness through a specific know-how, would be perceived as a HSE. In line with Chappelet's (2015) study, the sustainability is necessary to identify a sports event as a HSE, but as

\footnotetext{
${ }^{7}$ The parsimonious solution is the result of a computer-based simulation with regard to logical reminders. The assumption behind the algorithm is that the existing logical reminders (five in this study) would lead to different outcomes and that the given solution is the most parsimonious possible.
} 
mentioned by Bessy (2014), the event needs to find a strategic position that allows its differentiation from other sports events.

With a closer look at the truth table presented in Table 3, three events - the Trophées du Muveran (MUVE), the European Master of Golf in Crans-Montana (EU_MA) and the Tir historique de Morat (TIR_M) - refute the initial hypothesis. All of them are sustainable in their territory, and one of the three conditions of the differentiation strategy is present (the narrative for the 'Tir historique de Morat' and the symbols for the other two). As mentioned before, this is only partially true for the European Master of Golf in Crans-Montana. Indeed, when the proximity factor is considered (both in terms of space and sports practice) the event is perceived as a HSE. However, for the other two events, the proximity does not have an influence on their perception. Based on the parsimonious solution presented before, the 'Tir historique de Morat' is missing specific symbols to which people could relate to, while the 'Trophées du Muveran' is missing a narrative which would reinforce the uniqueness of the event.

\section{Conclusion}

Based on an exploratory research on heritage sporting events, this contribution presented the theoretical construction of this emerging concept and observed their different configurations in the French-speaking part of Switzerland. This is an important step on a broader study to understand HSEs and the opportunities they might represent for the host destination. On the one hand, it enables to understand the construction process of HSEs from an initial resource (a sports event) to a territorial resource (a HSE) as presented in Figure 1. On the other hand, it develops an emerging concept that needs to be further studied.

As it was presented before, one of the major difficulties in a research on HSEs is the identification of sports events that might be considered as such. Therefore, researchers 
need tools at their disposal to identify potential HSEs. The constituent elements that sustain the event in the host destination - namely the recurrence, the location, the local governance and the longevity - could be used to that purpose. They should not be seen as definitive characteristics, but rather as a way to observe the different configurations in which HSEs might exist. For instance, the ' $20 \mathrm{~km}$ of Lausanne' identified as a HSE in Table 1 was created in 1982 . However, according to the two generations principle by UNESCO discussed before, 50 years should be necessary to designate a heritage good. Furthermore, the proximity (both spatial and in terms of sports practice) sometimes also plays a part in the perception of a sports event as a HSE, as it was presented with the European Master of golf in Crans-Montana. Therefore, the local context and the perception of the event by the population need to be considered. As it was shown by the QCA, the sustainability of the event in the territory is necessary for the event to be perceived as a heritage good, but not sufficient. It is the differentiation process that enables the event to be seen as an authentic feature of the territory by the population. Either through the display of a unique know-how, either by particular narratives and symbols, the event distinguishes itself from other more or less similar events, to be perceived as a HSE. Taking into account the comments about the necessary conditions' test made before, it seems that the narrative is almost a necessary condition to identify a sports event as a HSE. In that perspective, a fuzzy-set QCA (fsQCA), where memberships in the interval between 0 and 1 are permitted, while retaining the two qualitative states of full membership and full non-membership, could give a slightly different parsimonious solution. Furthermore, the Swiss context in this study should also be considered. Indeed, the strong local autonomy in the Swiss political system (Ladner, Keuffer \& Baldersheim, 2015) and the association's regulations in the country might impact the configuration of the events, with regards to their governance. For instance, the Tour de France is owned 
by a private company (Amaury Sport Organisation) and not a non-for profit organisation or a public entity as expected from the theory, but might still be perceived as a HSE. In a broader perspective, the public sector usually prevails in the network surrounding events in Switzerland (Pinson, 2012) and in Europe (Di Gaetano \& Klemanski, 1993), while the corporate sector has a stronger influence in North America (Mossberg \& Getz, 2006). These comments about both the different types of configurations that might be observed in other contexts and the possible variations according to the coding type for the QCA, make an opening for future research.

\section{Managerial implications}

Although the primary purpose of this contribution was to present the theoretical construction behind the concept of HSEs and its different configurations in a given context, HSEs might also be interesting for local authorities engaged in sports events hosting strategies. These strategies are usually based on exogenous resources (international one-off events), but today this logic is challenged. On the one hand, it is more and more difficult for territories to be designated to host major sports events (due to the growing competition and the gigantism of those events). On the other hand, major events are questioned by the population and the public authorities. The demonstrations during the 2013 Confederations Cup in Brazil or the votes against the candidatures by the local population for the 2022 Olympics in the Canton of Grison, Switzerland, or the 2024 Olympics in Hamburg, Germany, are some examples showing that the logic behind sports events hosting strategies might need to be rethought. Although sports heritage is increasingly perceived as a potential catalyst of tourism and territorial development, it is usually considered through sports museums, hall of fame or tangible representations of this heritage (such as stadiums), but rarely the event. However, HSEs represent an opportunity to base the promotion and the development of the region on endogenous 
resources and the local identity. For instance, Batelli and Riou (2008) show, in their study about the Vendée Globe (a round-the-world single-handed yacht race, sailed non-stop and without assistance), how the Vendée department became the owner of the race and used it to promote the region to tourist, but also to investors and companies. The local authorities understood the opportunity the event represents to promote the region's nautical industry. In the same way, Ramshaw and Bottelberghe (2014), in a study about the Tour of Flanders, study the way the event is used to attract global tourism and investment interest, as well as developing tourism attractions related to the event heritage, such as the Tour Museum or a cycling trip planner integrating heritage sites related to the event. Active sport tourism events, such as the Tour of Flanders Cyclo (a participatory cycling events) studied by Derom and Ramshaw (2016), can also represent an opportunity for the host destination. The authors suggest that these events should employ sport heritage as a resource to develop future tourism initiatives to attract international active sport tourists. Besides, in an event portfolio perspective (Ziakas, 2010), HSEs and major international one-off events are not in competition, but complement one another to tackle the different aims of hosting strategies (Chappelet \& Pinson, 2015).

\section{Theoretical implications and future research}

To speak about sporting events in a heritage perspective is not new. The Running of the Bulls in Pamplona, the Heritage Classic in Ice Hockey, the Wimbledon Championship or the Arctic Winter Games are examples of events used in the academic literature and studied, most of the time, in the spectrum of sport tourism. However, these examples reflect different realities. Therefore, this contribution offers an approach in gaining a better understanding of what constitutes a HSE, and how it distinguishes itself from its more common counterparts. The framework presented in Figure 1 illustrates, through a variety of key concepts, the transformation of a sporting event (seen as an initial resource) 
into a HSE (a territorial resource). As mention above, this is a first important step in understanding HSEs and how they can contribute to sport tourism.

HSEs, observed in this contribution, are coming in different sizes and shapes. From international elite competitions (such as 'Athletissima' a Diamond League meeting in Athletics), to participatory running events (for instance, 'La Course de l'Escalade' in Geneva) and events in traditional Swiss sports (such as the 'Finales Nationales de la Race d'Hérens' a cow fighting competition), the concept of HSEs covers more than one reality. Furthermore, in relation to Gibson's (1998) tripartite categorization of sport tourism, these events might be referred to as event sport tourism, active sport tourism or nostalgia sport tourism. However, as mentioned by Ramshaw and Bottelberghe (2014, p.25), by interacting with both active sport tourism and event sport tourism, sport heritage is 'providing more potential avenues for tourism development'. Of course, as an exploratory research dealing with an emerging concept in a young field, this contribution is not pretending to any dogmatic exhaustiveness around the concept of HSEs. It explored and offered some thoughts on an emerging concept that might become important in sport tourism in the future, but further research is needed.

This contribution presented HSEs as having positive outcomes for the hosting destination. Future research may wish to consider the potential negative outcomes too. Indeed, HSEs can symbolize some dated perception of the place that might not fit the destination branding strategy. Furthermore, as shown by Moore, Richardson and Corkill (2014) in their study about the Isle of Mann TT Race (the oldest motorcycle road racing event), the 'official' narrative surrounding the event is contested. In this perspective, HSEs can become a source of conflict within the community around the local identity. However, to study their impacts, it is necessary to identify HSEs. As it was presented, since no list or label exists, one of the difficulties is to identify sports events that may be 
classified under this concept. One of the values of this study is in pinpointing some possible characteristics of HSEs, which might help in identifying potential HSEs. However, the Swiss, and to another extent European, context of this study might influence the configurations of the events perceived as HSEs. Therefore, it is necessary to broaden the observation of HSEs' configurations to other contexts. Furthermore, HSEs were presented in the study as non-transportable, since part of the heritage is linked to their location. This can be partly explained by the sample of events studied, but also to the difficulty to deal with mobile or transnational heritage (Leimgruber, 2010). However, sometimes the heritage component can be found solely in the event and not necessarily in the place. For instance, the Olympics conveys its own symbols and history to the places it goes to. The host destination can then benefit from this heritage before, during and after the event. In relation to Ramshaw and Gammon's (2015) study and the two types of HSEs presented before (whether they have heritage or competition as their primary focus), this might represent a third type of HSEs. These events have the capacity through time to build their own heritage, which is recognized wherever they go. Further research is needed to better understand HSEs and maybe offer a typology. Finally, QCA is a welladapted method to observe different configurations of conditions in a complex environment. If the csQCA used for this study gave interesting results (especially by showing clear configurations), further research might want to use fsQCA or multi-value QCA (mvQCA) to better capture the richness of the raw data. 


\section{Reference List}

Arcodia, C. V. \& Robb, D. A. (2000). A taxonomy of event management terms. In J. Allen, R. Harris, L. Jago, \& A. Veal, (Eds.), Proceedings of Events Beyond 2000: Setting the Agenda. Australian Centre for Event Management (pp. 154160). Sydney, Australian Center for Event Management.

Arnaud, C. (2012). Approche fonctionnelle et dynamique du portefeuille territorial d'évènements culturels. Manager la proximité pour une attractivité durable du territoire [Functional and dynamic approach of cultural events portfolio. Proximity management for a sustainable development of the territory] $(\mathrm{PhD}$ thesis). IMPGT, Aix-en-Provence. Retrieved February 15, 2016, from http://www.theses.fr/2012AIXM1076/document

Batelli, N., \& Riou, F. (2008). Le Vendée Globe, outil de marketing territorial [Vendée Globe, a territorial marketing tool]. ESPACES-PARIS-, 256, p. 24.

Bessy, O. (dir.) (2014). L'innovation dans l'événementiel sportif: De l'attractivité touristique au développement territorial [Innovation in sporting events: From tourist attractivity to territorial development]. Voiron: PUS.

Black, D., \& Van Der Westhuizen, J. (2004). The allure of global games for semiperipheral polities and spaces: A research agenda. Third World Quarterly, 25(7), 1195-1214.

Boisseaux, S., Knoepfel, P., Laesslé, M., \& Tippenhauer, L. (2012). Labellisation du patrimoine: une approche néo-institutionnaliste [Labellized heritage: A neoinstitutional approach]. Working paper de l'IDHEAP, Chaire Politiques publiques et durabilité, 10/2012.

Borghi, R., Mariotti, A., \& Safarzadeh, N. (dir.) (2011). Handbook on tourism \& recent heritage. Casamemoire \& mutual heritage. Retrieved November 14, 2015, from http://1.static.ecorpus.org/download/notice_file/1930051/Guide\%20Tourisme\%20et\%20Patrim oine\%20recent.pdf

Chalip, L. (2000). Polysemy and Olympic audiences: Lessons for sports marketing. Barcelona: Centre d'Estudis Olímpics UAB. Retrieved April 28, 2016, from http://olympicstudies.uab.es/pdf/wp097_eng.pdf 
Chappelet, J.-L. (2015). Heritage sporting events and place marketing. In M. Plevnik, I. Retar, R. Pišot, \& A. Obid (Eds.), Sustainable development of sport tourism (pp. 57-72). Koper: Annales University Press.

Chappelet, J. L., \& Pinson, J. (2015). Évolutions des politiques publiques d'accueil d'événements sportifs [The evolution of sports events hosting public policies]. Revue européenne de management du sport, 45, 8-16.

Chhabra, D., Healy, R., \& Sills, E. (2003). Staged authenticity and heritage tourism. Annals of Tourism Research, 30(3), 702-719.

Crawford, G. (2004). Consuming sport: Fans, sport and culture. International Journal of Sports Marketing and Sponsorship, 6(2), 47-62.

Cronqvist, L. (2011). Tosmana: Tool for small-N analysis [Computer programme] (Version 1.3.2.0).Trier: University of Trier.

Derom, I., \& Ramshaw, G. (2016). Leveraging sport heritage to promote tourism destinations: The case of the Tour of Flanders Cyclo event. Journal of Sport \& Tourism, 1-21. doi:10.1080/14775085.2016.1212393

Di Gaetano, A., \& Klemanski, J. S. (1993). Urban regimes in comparative perspective: The politics of urban development in Britain. Urban Affairs Review, 29(54), 5483.

Feddersen, A., \& Maennig, W. (2012). Sectoral labour market effects of the 2006 FIFA World Cup. Labour Economics, 19(6), 860-869.

Fleuriel, S., \& Raspaud, M. (2011). La course cycliste Paris-Roubaix : un enjeu patrimonial? [The cycling race Paris-Roubaix: A heritage issue]. In M.-M. Damien \& C. Dorvillé (Dir.), Le patrimoine de nos régions: ruine ou richesse future? (pp. 65-81). Paris: L'Harmattan.

Fourie, J., \& Santana-Gallego, M. (2011). The impact of mega-sport events on tourist arrivals. Tourism Management, 32(6), 1364-1370.

Gammon, S., Ramshaw, G., \& Waterton, E. (2013). Examining the Olympics: Heritage, identity and performance. International Journal of Heritage Studies, 19(2), 119124.

Getz, D. (2008). Event tourism: Definition, evolution, and research. Tourism Management, 29(2008), 403-428.

Gibson, H. J. (1998). Sport tourism: A critical analysis of research. Sport Management Review, 1(1), 45-76. 
Gumuchian, H., \& Pecqueur, B. (2007). La ressource territoriale [The territorial resource]. Paris: Economica.

Hall, C.-M. (1989). The definition and analysis of hallmark tourist events. Geojournal, 19(3), 263-268.

Hede, A.-M. (2005). Sports-events, tourism and destination marketing strategies: An Australian case study of Athens 2004 and its media telecast. Journal of Sport \& Tourism, 10(03), 187-200.

Hinch, T. D., \& de la Barre, K. (2007). Culture, sport and tourism: the case of the Artic winter games (Canada). In J. L. S. Higham (Ed.), Sport tourism destinations: issues, opportunities and analysis (pp. 260-273). London: Routledge.

Hinch, T., \& Higham, J. (2005). Sport, tourism and authenticity. European Sport Management Quarterly, 5(3), 243-256.

Hinch, T., \& Higham, J. (2011). Sport tourism development (Vol. 13). Bristol: Channel view.

Hinch, T., \& Ramshaw, G. (2014). Heritage sport tourism in Canada. Tourism Geographies: An International Journal of Tourism Space, Place and Environment, 16(2), 237-251.

Howard, P. (2003). Heritage: Management, interpretation, identity. London: Continuum.

Jago, L. K., \& Shaw, R. N. (1998). Special events: A conceptual and definitional framework. Festival Management and Event Tourism, 5(1/2), 21-32.

Ladner, A., Keuffer, N., \& Baldersheim, H. (2015). Tender No 2014. CE. 16. BAT. 031: Self-rule Index for Local Authorities. European Commission, (Release 1.0), $84 \mathrm{p}$.

Leimgruber, W. (2010, January-August). Switzerland and the UNESCO Convention on intangible Cultural Heritage. Journal of Folklore Research: An International Journal of Folklore and Ethnomusicology, 47(1/2), 161-196.

Marx, A., \& Dusa, A. (2011). Crisp-set qualitative comparative analysis (csQCA), contradictions and consistency benchmarks for model specification. Methodological Innovations Online, 6(2), 103-148.

Mason, D. S., \& Duquette, G. H. (2008). Urban Regimes and sport in North American cities: Seeking status through franchises, events and facilities. International Journal of Sport Management and Marketing, 3(3), 221-241. 
Mason, D. S., Duquette, G. H., \& Scherer, J. (2005). Heritage, sport tourism and Canadian junior hockey: nostalgia for social experience or sport place? Journal of Sport Tourism, 10(4), 253-271.

McCartney, G., \& Osti, L. (2007). From cultural events to sport events: A case study of cultural authenticity in the Dragon Boat Races. Journal of Sport \& Tourism, 12(1), 25-40.

Mesure, S., \& Savidan, P. (Dir.) (2006). Le dictionnaire des sciences humaines [Dictionary of Human Science]. Paris: PUF.

Misener, L., \& Mason, D. S. (2008). Urban regimes and the sporting events agenda: A cross-national comparison of civic development strategies. Journal of Sport Management, 22, 603-627.

Moore, R., Richardson, M., \& Corkill, C. (2014). Identity in the 'Road racing capital of the world': Heritage, geography and contested spaces. Journal of Heritage Tourism, 9(3), 228-245.

Mossberg, L., \& Getz, D. (2006). Stakeholder influences on the ownership and management of festival brands. Scandinavian Journal of Hospitality and Tourism, 6(4), 308-326.

Nora, P. (1984). Les lieux de mémoire. Tome I: La République [Sites of memories. Volume I: the Republic]. Paris: Gallimard.

Pfister, G. (2011). Lieux de mémoire/sites of memories and the Olympic Games: An introduction. Sport in Society, 14(4), 412-429.

Pinson, J. (2012). Analyse des réseaux sociaux appliquée à l'organisation d'événements sportifs: Le cas de la World Gymnaestrada Lausanne 2011 [Social network analysis applied to the organisation of sports events: The World Gymnaestrada Lausanne 2011]. Lausanne: Cahier de l'IDHEAP. 277/2012.

Pinson, J. (2016a). From the Olympic dream to a down to earth approach: Lausanne's sports events hosting strategy. Sport in Society, 19(6), 828-839.

Pinson, J. (2016b). Heritage sporting events in the territorial development. In M. D. Alvarez, A. Yüksel, \& F. M. Go (Eds.), Heritage tourism destinations: Preservation, communication and development (pp. 76-90). Wallingford: CABI Publishing.

Ragin, C. C. (2014). The comparative method: Moving beyond qualitative and quantitative strategies. Berkeley: University of California Press. 
Ragin, C. C., \& Davey, S. (2014). fs/QCA [Computer Programme] (Version 2.5). Irvine, CA: University of California.

Ramshaw, G. (2011). The construction of sport heritage attractions. Journal of Tourism Consumption and Practice, 3(1), 1-25.

Ramshaw, G. (2014). Too much Nostalgia? A decennial reflection on the Heritage Classic Ice Hockey event. Event Management, 18(4), 473-477.

Ramshaw, G., \& Bottelberghe, T. (2014). Pedaling through the past: Sport Heritage, tourism development, and the tour of Flanders. Tourism Review International, 18(1), 23-36.

Ramshaw, G., \& Gammon, S. (2005). More than just Nostalgia? Exploring the Heritage/Sport tourism Nexuas. Journal of Sport Tourism, 10(4), 229-241.

Ramshaw, G., \& Gammon, S. (2015). Heritage and sport. In E. Waterton \& S. Watson (Eds.), The Palgrave handbook of contemporary heritage research (pp. 248260). London: Palgrave Macmillan.

Rinaudo, C. (2005). Carnaval de Nice et carnavals indépendants: Les mises en scène festives du spectacle de l'authentique [The carnival of Nice and independent carnival: Festive settings for the spectacles of the authentic]. Sociologie et sociétés, 37(1), 55-68.

Ritchie, J.-R.-B. (1984). Assessing the impact of hallmark events: Conceptual and research issues. Journal of Travel Research, 23(2), 2-11.

Schneider, C. Q., \& Wagemann, C. (2010). Standards of good practice in qualitative comparative analysis (QCA) and fuzzy-sets. Comparative Sociology, 9(3), 397418.

Sofield, T. H. B. (2003). Sport tourism: From binary division to quadripartite construct. Journal of Sport \& Tourism, 8(3), 144-165.

Taks, M. (2016). The rise and fall of mega sports events: The future is in non-mega sport events. In Y. V. Auweele, E. Cook, \& J. Parry (Eds.), Ethics and governance in sport: The future of sport imagined (pp. 84-93). London: Routledge.

UNESCO. (2003). Convention for the safeguarding of the intangible cultural heritage. Retrieved November 19, 2015, from http://www.unesco.org/culture/ich/index.php?lg=fr\&pg=00006

UNESCO. (2008). Carnival of Barranquilla. Retrieved November 19, 2015, from http://www.unesco.org/culture/ich/en/RL/carnival-of-barranquilla-00051 
UNESCO. (2009). Dragon boat festival. Retrieved November 19, 2015, from

http://www.unesco.org/culture/ich/index.php?lg=en\&pg=00011\&RL=00225

UNESCO. (2010a). Naadam, Mongolian traditional festival. Retrieved July 15, 2016, from http://www.unesco.org/culture/ich/en/RL/naadam-mongolian-traditionalfestival-00395?RL=00395

UNESCO. (2010b). Kirkpinar oil wrestling festival. Retrieved November 19, 2015, from http://www.unesco.org/culture/ich/index.php?RL=00386

UNESCO. (2011). Equitation in the French tradition. Retrieved November 19, 2015, from http://www.unesco.org/culture/ich/fr/RL/00440

Vuignier, R. (2015). Cross-border place branding: The case of Geneva highlighting multidimensionality of places and the potential role of politico-institutional aspects. In S. Zenker \& B. P. Jacobsen (Eds.), Inter-regional place branding: Best practices, challenges and solutions (pp. 63-72). Cham: Springer.

Wang, N. (1999). Rethinking authenticity in tourism experience. Annals of Tourism Research, 26(2), 349-370.

Waterton, E., Smith, L., \& Campbell, G. (2006). The utility of discourse analysis to heritage studies: The Burra Charter and social inclusion. International Journal of Heritage Studies, 12(4), 339-355.

Wood, J. (2005). Olympic opportunity: Realizing the value of sports heritage for tourism in the UK. Journal of Sport \& Tourism, 10(4), 307-321.

Ziakas, V. (2010). Understanding an event portfolio: The uncovering of interrelationships, synergies, and leveraging opportunities. Journal of Policy Research in Tourism, Leisure and Events, 2(2), 144-164. 


\section{Appendix}

\section{Appendix 1}

Table 6: Truth table for M2, sustainability conditions

\begin{tabular}{llccccccc}
\hline \hline Row & \multicolumn{1}{c}{ Cases } & $\begin{array}{c}\mathbf{N}^{\circ} \text { of } \\
\text { cases }\end{array}$ & AGE & RECU & LOC & GOV & HSE & $\begin{array}{c}\text { Consistency } \\
\text { of HSE }=\mathbf{1}\end{array}$ \\
\hline & PDG, MT_FR, FN_CR, & & & & & & & \\
1 & MC_SA, MUVE, BAMB, & 9 & 1 & 1 & 1 & 1 & $\mathrm{C}$ & 0.44 \\
& CP_NA,C_NOEL, TIR_M & & & & & & & \\
& ESCA, 20KM, ATHLE, & & & & & & & \\
2 & FIB, SI_ZI, PX_LS, JLV, & 9 & 0 & 1 & 1 & 1 & $\mathrm{C}$ & 0.67 \\
& MARA, LAAX & & & & & & & \\
3 & BO,CHIG, EU_MAS & 3 & 1 & 1 & 1 & 0 & $\mathrm{C}$ & 0.67 \\
4 & MAR_LS, TRANS & 2 & 0 & 1 & 1 & 0 & 0 & 0.00 \\
5 & REDB & 1 & 0 & 0 & 0 & 0 & 0 & 0.00 \\
6 & - & 0 & 1 & 1 & 0 & 0 & - & - \\
7 & - & 0 & 1 & 1 & 0 & 1 & - & - \\
8 & - & 0 & 1 & 0 & 0 & 0 & - & - \\
9 & - & 0 & 1 & 0 & 0 & 1 & - & - \\
10 & - & 0 & 1 & 0 & 1 & 0 & - & - \\
11 & - & 0 & 0 & 1 & 0 & 1 & - & - \\
12 & - & 0 & 0 & 0 & 0 & 1 & - & - \\
13 & - & 0 & 0 & 0 & 1 & 1 & - & - \\
14 & - & 0 & 0 & 1 & 0 & 0 & - & - \\
15 & - & 0 & 1 & 0 & 1 & 1 & - & - \\
16 & - & 0 & 0 & 0 & 1 & 0 & - & - \\
\hline \hline
\end{tabular}

\section{Appendix 2}

Table 7: Truth table for M3, differentiation conditions

\begin{tabular}{|c|c|c|c|c|c|c|c|}
\hline Row & Cases & $\begin{array}{l}\mathbf{N}^{\circ} \text { of } \\
\text { cases }\end{array}$ & NAR & SYMB & KNO-H & HSE & $\begin{array}{c}\text { Consistency of } \\
\text { HSE }=1\end{array}$ \\
\hline 1 & PDG & 1 & 1 & 1 & 1 & 1 & 1.00 \\
\hline 2 & FIB & 1 & 0 & 0 & 1 & 1 & 1.00 \\
\hline 3 & $\begin{array}{l}\text { ESCA, 20KM, ATHLE, MT_FR, } \\
\text { SI_ZI, BO, LAAX }\end{array}$ & 7 & 1 & 1 & 0 & $\mathrm{C}$ & 0.86 \\
\hline 4 & $\begin{array}{l}\text { FN_CR, PX_LS, CHIG, MC_SA, } \\
\text { REDB }\end{array}$ & 5 & 1 & 0 & 1 & C & 0.80 \\
\hline 5 & MUVE, EU_MAS, MAR_LS & 3 & 0 & 1 & 0 & 0 & 0.00 \\
\hline 6 & $\begin{array}{l}\text { BAMB, CP_NA, JLV, TRANS, } \\
\text { C_NOEL, MARA }\end{array}$ & 6 & 0 & 0 & 0 & 0 & 0.00 \\
\hline 7 & TIR_M & 1 & 1 & 0 & 0 & 0 & 0.00 \\
\hline 8 & - & 0 & 0 & 1 & 1 & - & - \\
\hline
\end{tabular}

